LOURENÇÃO, A.L.; MELO, A.M.T.; SIQUEIRA, W.J.; COLARICCIO, A.; MELO, P.C.T. Avaliação da resistência de acessos de tomateiro a tospovírus e a geminivírus. Horticultura Brasileira, Brasília, v.22, n.2, p.193-196, abril-junho 2004.

\title{
Avaliação da resistência de acessos de tomateiro a tospovírus e a geminivírus
}

\author{
André Luiz Lourenção ${ }^{1}$; Arlete M. T. de Melo ${ }^{1}$; Walter José Siqueira ${ }^{1}$; Addolorata Colariccio ${ }^{2}$; Paulo \\ César T. de Melo ${ }^{3}$ \\ ${ }^{1}$ Instituto Agronômico (IAC), C. Postal 28, 13001-970 Campinas-SP; E-mail: andre@iac.sp.gov.br; nstituto Biológico, C. Postal 7119 , \\ 01064-970 São Paulo-SP; ${ }^{3}$ USP-ESALQ, C. Postal 9, 13418-900 Piracicaba-SP
}

\section{RESUMO}

Treze linhagens avançadas e três cultivares de tomateiro foram avaliadas em condições de campo para resistência a tospovírus e a geminivírus, em Campinas (SP). O germoplasma avaliado compreendeu linhagens do grupo IAC e as cultivares Stevens, Franco e IPA-5. Um mesmo experimento foi instalado em duas épocas. Na primeira, o experimento foi conduzido de $12 / 2001$ a $2 / 2002$, e a única espécie de tospovírus incidente foi Tomato chlorotic spot virus (TCSV). Na segunda época, de 7 a 9/2002, houve infecção por Tomato yellow vein streak virus (TYVSV), sendo a avaliação realizada mediante determinação da porcentagem de plantas infectadas e pela intensidade dos sintomas, medida por escala de notas. Não houve discriminação dos tratamentos com base no primeiro critério, mas o uso de notas permitiu a diferenciação do germoplasma, com destaque para a linhagem IAC-S3-16. Considerando-se ambas as épocas, confirmou-se a suscetibilidade de 'IPA-5' aos dois patógenos e demonstrou-se o comportamento de resistência de 'Franco' a TCSV e a TYVSV. Ainda deve ser destacado o desempenho das linhagens IAC-S3-54, IAC-S3-318, IAC-S4-39 e IAC-SVS-1, com baixas porcentagens de infecção por TCSV, e notas de sintomas de TYVSV próximas à média de 'Franco', caracterizando-se como promissoras para obtenção de cultivares com resistência aos dois vírus.

Palavras-chave: Lycopersicon esculentum, Tomato chlorotic spot virus (TCSV), Tomato yellow vein streak virus (TYVSV), resistência de plantas a doenças.

\begin{abstract}
Evaluation of tomato accessions for tospovirus and geminivirus resistance

Thirteen lines and three commercial tomato cultivars were screened for tospovirus and geminivirus resistance under field conditions, in Campinas, São Paulo State, Brazil. The germplasm comprised advanced IAC lines plus cultivars Stevens, Franco and IPA-5. The same experiment was carried out in two planting seasons. In the first (December 2001 to February 2002), only Tomato chlorotic spot virus (TCSV) occurred in the field. In the second (July to September 2002), Tomato yellow vein streak virus (TYVSV) was identified in the experimental area, and the evaluation was carried out through counting of infected plants and by symptom intensity scoring by notes. There were no treatment differences by using the first criterion, but the score evaluation was effective in detecting differences among genotypes; line IAC-S3-16 showed an outstanding performance. Considering the two trials, the susceptibility of 'IPA5 ' to both pathogens was confirmed; in addition, resistance of 'Franco' to TCSV and TYVSV was observed. Lines IAC-S3-54, IAC-S3318, IAC-S4-39 and IAC-SVS-1 could be distinguished for the low infection by TCSV. So, these lines can be considered as promising genetic material to obtain cultivars with resistance to both viruses and good agronomic traits.
\end{abstract}

Keywords: Lycopersicon esculentum, Tomato chlorotic spot virus (TCSV), Tomato yellow vein streak virus (TYVSV), plant disease resistance.

\section{(Recebido para publicação em 9 de abril de 2003 e aceito em 4 de fevereiro de 2004)}

$\mathrm{O}$ programa de melhoramento do tomateiro do IAC visa à obtenção de cultivares com boas características agronômicas, destacando-se alta produtividade, boa qualidade dos frutos e resistência às principais pragas e doenças da cultura (Nagai, 1993). Atualmente, ênfase está sendo dada à seleção de linhagens com resistência a tospovírus e geminivírus (Lourenção et al., 2001; Matos et al., 2003).

Os tospovírus causam o conjunto de sintomas denominado vulgarmente no Brasil como "vira-cabeça-do-tomateiro" e assumem grande importância como doença da cultura, principalmente nas épocas mais quentes do ano, em diferentes regiões do mundo (German et al.,
1992; Pozzer et al., 1996). No Brasil, infectando tomateiros, já foram identificadas as espécies Tomato spotted wilt virus (TSWV), Tomato chlorotic spot virus (TCSV), Groundnut ringspot virus (GRSV), e Chrysanthemum stem necrosis virus (CSNV), variando a predominância da espécie em função da região (Nagata et al., 1995; Ávila et al., 1998, Colariccio et al., 2000). Atuam como vetores de tospovírus tripes dos gêneros Frankliniella, Thrips e Scirtothrips (Mound, 1996).

Os geminivírus constituem outro grupo de vírus de grande importância para o tomateiro nas principais regiões do mundo onde essa solanácea é cultivada (Brown e Bird, 1992; Faria et al.,
2000; Moriones e Navas-Castillo, 2000). Na Europa, África e Sudeste Asiático, a espécie Tomato yellow leaf curl virus (TYLCV) encontra-se amplamente disseminada, sendo responsável por elevadas perdas na produção (Czosnek et al., 1990). No estado de São Paulo, nos últimos anos, o geminivírus mais comumente encontrado infectando tomateiros pertence à espécie descrita por Faria et al. (1997) como Tomato yellow vein streak virus (TYVSV). Assim como para outras espécies de geminivírus de importância para essa e outras culturas, os insetos transmissores são moscas-brancas do complexo Bemisia tabaci (Genn.) (Brown, 1994; Bedford et al., 1994; Faria et al., 2000). 
Tabela 1. Porcentagem média de infecção por Tomato chlorotic spot virus (TCSV) em quatorze linhagens e duas cultivares de tomateiro em condições de campo. Campinas, IAC, 2001/2002.

\begin{tabular}{|c|c|c|c|}
\hline \multirow[b]{2}{*}{ Genótipo } & \multirow[b]{2}{*}{ Genealogia } & \multicolumn{2}{|c|}{ Plantas infectadas (\%) } \\
\hline & & $\begin{array}{c}1^{\text {a }} \text { avaliação } \\
(04 / 01 / 02)^{1}\end{array}$ & $\begin{array}{r}2^{a} \text { avaliação } \\
(04 / 02 / 02)^{1}\end{array}$ \\
\hline IAC-S4-3-18C & ('Stevens' x 'IPA-6') x 'IPA-6' & $0,0 c$ & $4,4 \mathrm{c}$ \\
\hline IAC-S5-55 & Seleção em IAC-TySw5 & $3,0 \mathrm{bc}$ & $5,1 \mathrm{c}$ \\
\hline IAC-SVS-1 & ('Stevens' x 'IPA-6') x 'IPA-6' & $0,0 \mathrm{c}$ & $7,5 \mathrm{c}$ \\
\hline IAC-S3-318 & IAC-TySw5 x IAC-S4-3-18C & $1,0 c$ & $8,8 \mathrm{c}$ \\
\hline IAC-S3-54 & IAC-TySw5 x IAC-S4-4-16A & $6,5 \mathrm{bc}$ & $9,6 b c$ \\
\hline IAC-S4-39 & 'Gem Pride' x TWN-03/98 & $6,1 \mathrm{bc}$ & $11,4 b c$ \\
\hline 'Stevens' & Lycopersicon esculentum $\times$ L. peruvianum & $1,5 b c$ & $12,0 \mathrm{bc}$ \\
\hline IAC-S3-518 & TWN-05/98 x IAC-S4-3-18C & $5,8 \mathrm{bc}$ & $12,2 \mathrm{bc}$ \\
\hline IAC-S3-29 & TWN-02/98 x IAC-TySw5 & $7,4 \mathrm{bc}$ & $13,4 b c$ \\
\hline IAC-S4-598 & 'Gem Pride' x TWN-05/98 & $6,0 \mathrm{bc}$ & $13,7 \mathrm{bc}$ \\
\hline 'Franco' & & $10,3 b c$ & $13,7 \mathrm{bc}$ \\
\hline IAC-S4-416 & 'Gem Pride' x IAC-S4-4-16A & $11,2 b c$ & $13,7 \mathrm{bc}$ \\
\hline IAC-S3-55 & IAC-TySw5 x TWN-05/98 & $10,0 \mathrm{bc}$ & $15,1 b c$ \\
\hline IAC-S3-16 & IAC-S4-4-16A x IAC-TySw5 & $9,1 \mathrm{bc}$ & $20,2 b c$ \\
\hline IAC-S4-298 & TWN-02/98 x 'Gem Pride' & $14,9 b$ & $34,0 \mathrm{~b}$ \\
\hline 'IPA-5' & & $39,0 a$ & $79,9 a$ \\
\hline Média & & 8,2 & 17,2 \\
\hline C.V. $(\%)$ & & 53,5 & 37,3 \\
\hline
\end{tabular}

${ }^{1}$ Médias seguidas de mesma letra na coluna não diferem significativamente entre si pelo teste de Tukey a 5\%.

A alta incidência de TYVSV em lavouras de tomate em São Paulo, no início desta década, tem produzido decréscimos significativos na produção. O volume de tomate comercializado na CEAGESP nos anos 1997-2001 variou entre 215.000 a $236.000 \mathrm{t}$, sendo que em 2002 o total caiu para cerca de 140.000 t (Agrianual, 2003), reflexo direto de elevadas infecções de geminivírus nas principais regiões produtoras do estado.

Devido às dificuldades encontradas no combate aos insetos vetores, tanto para tospovírus (tripes) quanto para geminivírus (mosca-branca), há necessidade de se considerar outras alternativas no controle dessas duas doenças. Dessa forma, a identificação de fontes de resistência a ambos os patógenos e sua posterior incorporação em genótipos comerciais são pesquisas que merecem ser priorizadas, constituindo-se no método ideal de controle. Nessa linha, o objetivo do presente trabalho foi avaliar a resistência a tospovírus e a geminivírus em linhagens avançadas e em cultivares de tomateiros, em condi- ções de infecção natural de campo, na região de Campinas (SP).

\section{MATERIAL E MÉTODOS}

\section{Avaliação de infecção por tospovírus}

Um experimento foi conduzido no Centro Experimental de Campinas, pertencente ao IAC, no ano agrícola 2001/ 2002. O germoplasma avaliado compreendeu 13 linhagens IAC, sendo uma delas, IAC-S4-3-18C, considerada resistente (Lourenção et al., 2001), e as cultivares Stevens, também tida como resistente a tospovírus, Franco e IPA-5, padrão de suscetibilidade. Esses genótipos foram semeados em 14/11/ 2001, em bandejas de poliestireno expandido, contendo 128 células preenchidas com substrato comercial. O transplante para campo foi realizado 27 dias após a semeadura. O delineamento utilizado foi o de blocos ao acaso, com os dezesseis tratamentos repetidos cinco vezes. A parcela foi constituída de duas linhas de $3 \mathrm{~m}$, com sete plantas por li- nha, totalizando 14 plantas. Foi utilizado espaçamento de $1 \mathrm{~m}$ entre linhas e $0,5 \mathrm{~m}$ entre plantas. A adubação foi feita no sulco, com a fórmula 4-14-8, de acordo com as necessidades verificadas com a análise do solo. Também foi realizada adubação de cobertura com sulfato de amônio. Em todo o ciclo das plantas não foram realizadas aplicações de defensivos. Em duas datas (04/01 e 04/02/2002), foram feitas avaliações, em cada parcela, da porcentagem de plantas com sintomas de tospovirose. Para identificação do tospovírus, em cada parcela foram colhidos ramos com folhas e, quando possível, com frutos, de plantas com sintomas para realização de testes biológicos e sorológicos, conforme Colariccio et al. (2001).

Avaliação de infecção por geminivírus

O experimento foi instalado na mesma área experimental descrita no item anterior. O germoplasma utilizado e os procedimentos de obtenção das mudas e de condução do experimento também foram os mesmos. A semeadura foi rea- 
Tabela 2. Porcentagem média de infecção e notas médias ${ }^{1}$ de avaliação de sintomas causados por Tomato yellow vein streak virus (TYVSV), em treze linhagens e três cultivares de tomateiro em condições de campo. Campinas, IAC, 2002.

\begin{tabular}{lll}
\hline \multicolumn{1}{c}{ Genótipo } & Plantas infectadas ${ }^{2}(\%)$ & \multicolumn{1}{c}{ Nota $^{2}$} \\
\hline IAC-S3-16 & $65,8 \mathrm{a}$ & $2,28 \mathrm{f}$ \\
'Franco' & $41,3 \mathrm{a}$ & $2,65 \mathrm{ef}$ \\
IAC-S3-54 & $51,4 \mathrm{a}$ & $2,65 \mathrm{ef}$ \\
IAC-S3-318 & $39,1 \mathrm{a}$ & $2,67 \mathrm{ef}$ \\
IAC-S4-39 & $53,3 \mathrm{a}$ & $2,74 \mathrm{def}$ \\
IAC-SVS-1 & $69,3 \mathrm{a}$ & $2,84 \mathrm{cdef}$ \\
IAC-S4-598 & $49,1 \mathrm{a}$ & $2,93 \mathrm{cdef}$ \\
IAC-S3-29 & $49,6 \mathrm{a}$ & $3,17 \mathrm{bcdef}$ \\
IAC-S4-298 & $47,2 \mathrm{a}$ & $3,25 \mathrm{bcde}$ \\
IAC-S4-3-18C & $68,6 \mathrm{a}$ & $3,35 \mathrm{bcde}$ \\
IAC-S3-518 & $64,5 \mathrm{a}$ & $3,55 \mathrm{bcde}$ \\
IAC-S4-416 & $68,9 \mathrm{a}$ & $3,75 \mathrm{bcd}$ \\
IAC-S5-55 & $66,5 \mathrm{a}$ & $3,84 \mathrm{abc}$ \\
'Stevens' & $63,7 \mathrm{a}$ & $4,03 \mathrm{ab}$ \\
IAC-S3-55 & $55,7 \mathrm{a}$ & $4,27 \mathrm{ab}$ \\
'IPA-5' & $56,4 \mathrm{a}$ & $4,89 \mathrm{a}$ \\
\hline Média & 56,9 & 3,30 \\
\hline C.V. (\%) & 23,6 & 10,83 \\
\hline
\end{tabular}

${ }^{1}$ Escala de notas de 1 a 5 , onde 1 = ausência de sintomas, ... e 5 = clorose severa e enrugamento acentuado dos folíolos no terço superior da planta.

${ }^{2}$ Médias seguidas de mesma letra na coluna não diferem significativamente entre si pelo teste de Tukey a 5\%.

lizada em 10/06/2002 e o transplante das mudas feito 30 dias depois. Aos 43 dias após o transplante foi avaliada a porcentagem de plantas com sintomas de geminivirose. A seguir, foi realizada uma avaliação da severidade da doença, por meio de escala de notas atribuídas por dois avaliadores de forma independente, a cada planta sintomática da parcela. Foi empregada uma escala variando de 1 a 5, adaptada de Ferreira et al. (1999) e ilustrada por Matos (2001), em que 1=ausência de sintomas, 2=ligeira descoloração dos folíolos, $3=$ descoloração com início de enrugamento dos folíolos, 4=descoloração e enrugamento dos folíolos e $5=$ clorose severa e enrugamento acentuado dos folíolos no terço superior da planta. Para identificação do geminivírus, foi feita sua caracterização molecular, seqüenciando-se o fragmento obtido através de PCR com o par de primers degenerados PAC1v1978/PAV1c715, que amplifica parte do gene rep (ORF
18C, IAC-SVS-1 e IAC-S3-318 foram as mais resistentes, destacando-se as duas primeiras com $0 \%$ de infecção. $\mathrm{Na}$ segunda avaliação, realizada após um mês, houve aumento nas taxas médias de infecção, praticamente dobrando a média geral dos tratamentos (Tabela 1). Todavia, manteve-se a tendência de infecção entre os acessos, tendo 'IPA-5' e 'IAC-S4-298' diferido das quatro linhagens IAC que apresentaram médias variando de 4,4 a 8,8\%. As demais linhagens e as cultivares Stevens e Franco não diferiram dessas quatro linhagens mais resistentes.

Foi verificado um gradiente de infecção entre as linhagens IAC, que variou de 4,4 a 34,0\%, resultando em diferenças no nível de resistência ao vírus, embora todas essas linhagens tenham em sua genealogia a cultivar Stevens. Em experimentos de avaliação de resistência de tomateiros a tospovírus conduzidos em Campinas (1999/2000) e em Paulínia (1998/99), onde predominou a espécie TCSV, Lourenção et al. (2001) obtiveram resultados semelhantes. Nesses locais, foi observado extenso gradiente de infecção entre linhagens dos grupos IAC e TWN, embora todas tenham se originado de cruzamentos entre 'Stevens' e 'IPA-6' e tenham sido selecionadas a partir de plantas sem sintomas, sob mesmas condições experimentais.

Deve ser ressaltado o índice de infecção de 'Franco', híbrido desenvolvido pela Seminis Vegetable Seeds para resistência a geminivírus, que atingiu $13,7 \%$ na segunda avaliação, média muito próxima da de 'Stevens' (12,0\%), considerado como padrão de resistência. Além disso, nas duas avaliações, 'Franco' não diferiu dos tratamentos mais resistentes, demonstrando possuir resistência a TCSV.

\section{RESULTADOS E DISCUSSÃO}

\section{Avaliação de infecção por tospovírus}

$\mathrm{Na}$ área experimental, a única espécie de tospovírus detectada foi TCSV, em ambas as avaliações. Na primeira, as taxas médias de infecção variaram de 0,0 a 39,0\% (Tabela 1). 'IPA-5' mostrouse a cultivar mais suscetível, com $39 \%$ das plantas infectadas, diferindo significativamente dos demais tratamentos. Por sua vez, as linhagens IAC-S4-3-
Avaliação da infecção por geminivírus

O geminivírus presente no experimento foi identificado como Tomato yellow vein streak virus (TYVSV), espécie que vem incidindo nos últimos anos sobre tomateiros em áreas experimentais do CEC e também em lavouras do cinturão verde de Campinas (Faria et al., 1997; Matos et al., 2003). A incidência do vírus atingiu toda a área do experimento, causando índices de infec- 
ção que oscilaram de 39,1 (IAC-S3-318) a $69,3 \%$ (IAC-SVS-1), embora sem diferenças entre os tratamentos (Tabela 2).

Com relação às notas de intensidade de sintomas, os valores variaram de 2,28, que correspondeu à média da linhagem IAC-S3-16, a 4,89, relativa à cultivar IPA-5, valor próximo da nota máxima. Para esse critério, houve discriminação entre os tratamentos, destacando-se a resistência da linhagem IACS3-16, derivada de cruzamento entre IAC-S4-4-16A, resistente a tospovírus, e IAC-TySw5, fonte de resistência a geminivírus. Embora com valor absoluto inferior ao de 'Franco', IAC-S3-16 não diferiu desta cultivar, cuja resistência ao TYVSV havia sido observada por Matos et al. (2003), em experimento com exposição precoce de tomateiros a moscas-brancas virulíferas.

É interessante observar que, dentre os tratamentos com nota média inferior a 3, situou-se a linhagem IAC-SVS-1, com 2,84, cuja genealogia não contém 'IAC-TySw5' nem 'Gem Pride', ambos resistentes ao geminivírus. Os demais tratamentos, que também não têm 'IACTySW5' e/ou 'Gem Pride' como genitores compreenderam as linhagens IAC-S4-3-18C (3,53 de nota média), IAC-S3-518 $(3,55)$ e as cultivares Stevens $(4,03)$ e IPA-5 $(4,89)$, cujas médias diferiram da linhagem mais resistente, IAC-S3-16.

Com base nos dois experimentos, confirmou-se a suscetibilidade de 'IPA5' a ambos os patógenos, caracterizando-a como um bom padrão diferencial de suscetibilidade para estudos deste tipo. Conforme discutido anteriormente, deve ser enfatizado o comportamento de resistência de 'Franco' a TYVSV e a TCSV, constituindo-se em cultivar com características vantajosas para plantio em locais e épocas em que um ou os dois vírus tenham alta incidência. Devem ser destacados, ainda, os desempenhos das linhagens IAC-S3-54, IAC-S3318, IAC-S4-39 e IAC-SVS-1, que exibiram baixas porcentagens de infecção a TCSV, entre 7,5 e $11,4 \%$, e notas de sintomas de geminivírus entre 2,65 e 2,84 , bastante próximas da média de 'Franco'. Portanto, essas linhagens são promissoras para a obtenção de cultivares com resistência a ambos os patógenos, uma vez que apresentam boas características agronômicas.

\section{AGRADECIMENTOS}

Ao CNPq, pela concessão de bolsa de pesquisa ao primeiro autor do trabalho.

\section{LITERATURA CITADA}

AGRIANUAL - Agrianual 2003. Anuário da Agricultura Brasileira. FNP Consultoria e Comércio Ltda., São Paulo, 544 p.

ÁVILA, A.C.; POZZER, L.; BEZERRA, I.; KORMELINK, R.; PRINS, M.; PETERS, D.; NAGATA, T.; KITAJIMA, E.; RESENDE, R. Diversity of tospoviruses in Brazil. In: INTERNATIONAL SYMPOSIUM ON TOSPOVIRUSES AND THRIPS IN FLORAL AND VEGETABLE CROPS, 4., 1998, Wageningen. Abstracts... Wageningen: 1998. p.32-34.

BEDFORD, I.D.; BRIDDON, R.W.; BROWN, J.K.; ROSELL; MARKHAM, P.G. Geminivirus transmission and biological characterization of Bemisia tabaci (Gennadius) biotypes from different geographic regions. Annals of Applied Biology, v.125, p.311-325, 1994.

BROWN, J.K. Current status of Bemisia tabaci as a plant pest and virus vector in agroecosystems worldwide. FAO Plant Protection Bulletin, v.42, p.3-32, 1994.

BROWN, J.K.; BIRD, J. Whitefly-transmitted geminiviruses and associated disorders in the Americas and the Caribbean Basin. Plant Disease, v.76, p.220-225, 1992.

COLARICCIO, A.; EIRAS, M.; CHAVES, A.L.R.; LOURENÇÃO, A.L.; MELO, A.M.T.; SIQUEIRA, W.J. Detecção do "Chrysanthemum stem necrosis virus" em tomateiro no Estado de São Paulo. Summa Phytopathologica, v.25, n.2, p.252-254, 2000.

COLARICCIO, A.; EIRAS, M.; CHAVES, A.L.R.; ROGGERO, P.; CHAGAS, C.M. Diversidade de tospovírus em diferentes regiões produtoras de olerícolas do Estado de São Paulo. Summa Phytopathologica, v.27, p.177-182, 2001.

CZOSNEK, H.; NAVOT, N.; LATERROT, H. Geographical distribution of Tomato yellow leaf curl virus. A first survey using a specific DNA probe. Phytopathologica Mediterranea, v.29, p.16, 1990.
FARIA, J.C.; SOUZA-DIAS, J.A.C.; SLACK, S.A.; MAXWELL, D.P. A new geminivirus associated with tomato in the State of São Paulo, Brazil. Plant Disease, v.81, p.423, 1997.

FARIA, J.C.; BEZERRA, I.C.; ZERBINI, F.M.;RIBEIRO, S.G.; LIMA, M.F. Situação atual das geminiviroses no Brasil. Fitopatologia Brasileira, Brasília, v.25, p.125-137, 2000.

FERREIRA, P.T.O.; BEZERRA, I.C.; VILLASBÓAS, G.L.; RIBEIRO, S.G.; GIORDANO, L.B. Avaliação de fontes de resistência a isolado de geminivírus com genoma bipartido transmitido por Bemisia argentifolii em Lycopersicon spp. Fitopatologia Brasileira, Brasília, v.24, p.131135, 1999.

GERMAN, T.L.; ULLMAN, D.E.; MOYER, J.W. Tospoviruses: diagnosis, molecular biology, phylogeny, and vector relationships. Annual Review of Phytopathology, v.30, p.315-348, 1992. LOURENÇÃO, A.L.; SIQUEIRA, W.J.; MELO, A.M.T.; MELO, P.C.T.; COLARICCIO, A.; FONTE, L.C.; CHAVES, A.L.R. Avaliação da resistência a tospovírus em cultivares e linhagens de tomateiro. Summa Phytopathologica, v.27, p.1723, 2001.

MATOS, E.S. Avaliação de tomateiro para resistência a tospovírus e geminivírus. Campinas: Instituto Agronômico, 2001. 83 p. (Tese mestrado) MATOS, E.S.; SIQUEIRA, W.J.; LOURENÇÃO, A.L.; MELO, A.M.T.; SAWAZAKI, H.E.; SOUZA-DIAS, J.A.C.; COLARICCIO, A. Resistência de genótipos de tomateiro a um isolado de geminivírus do cinturão verde de Campinas, São Paulo. Fitopatologia Brasileira. v.28, p. 159-165, 2003.

MORIONES, E.; NAVAS-CASTILLO, J. Tomato yellow leaf curl virus, an emerging virus complex causing epidemics worldwide. Virus Research, v.71, p.123-134, 2000.

MOUND, L.A. The Thysanoptera vector species of Tospoviruses. Acta Horticulturae, v.431, p.298307, 1996.

NAGAI, H. Tomate. In: FURLANI, A.M.C.; VIEGAS, G.P. (eds.). O melhoramento de plantas no Instituto Agronômico. Campinas: Instituto Agronômico, 1993. p.301-313.

NAGATA, T.; ÁVILA, A.C.; TAVARES, P.C.M.; BARBOSA, C.J.; JULIATTI, F.C.; KITAJIMA, E.W. Occurrence of different tospoviruses in six States of Brazil. Fitopatologia Brasileira, Brasília, v.20, p.90-95, 1995.

POZZER, L.; RESENDE, R.O.; LIMA, M.I.; KITAJIMA, E.W.; GIORDANO, L.B.; ÁVILA, A.C. Tospovírus: uma visão atualizada. Revisão Anual de Patologia de Plantas, v.4, p.95-148, 1996.

ROJAS, M.R.; GILBERTSON, R.L.; RUSSEL, D.R.; MAXWELL, D.P. Use of degenerate primers in the polymerase chain reaction to detect whitefly-transmitted geminiviruses. Plant Disease, v.77, p.340-347, 1993. 